\title{
Breast Cancer in Western Iraq: Clinicopathological Single Institution Study
}

\author{
Arkan Obaid Jasim Al-Isawi \\ Pathology Department, College of Medicine, Anbar University, Ramadi, Iraq \\ Email: arkanjas@yahoo.com
}

Received 10 March 2016; accepted 14 April 2016; published 19 April 2016

Copyright (C) 2016 by author and Scientific Research Publishing Inc.

This work is licensed under the Creative Commons Attribution International License (CC BY). http://creativecommons.org/licenses/by/4.0/

\begin{abstract}
Background: Breast cancer is the most frequent malignancy of women worldwide; In Iraq, it ranks first among cancers diagnosed in women, but studies on breast cancer among women in Western Iraq are limited. Breast cancer rate in Arabic countries is lower than that in West nations and more common in younger age. The aim of this study is to estimate age of presentation, stage, grade, type and side of tumor and their comparison with other Iraqi regions as well as with some Arabic and West countries. Materials and Methods: This is a descriptive study conducted between $1^{\text {st }}$ of February 2011 to $30^{\text {th }}$ of January 2015 in Western Iraq. 292 cases of breast cancer were enrolled in this study, including 206 cases of mastectomy and 86 cases of lumpectomy. Results: Average age at diagnosis: 47.16 (SD: 12.15), median age at diagnosis: 45 with mode of: 40 . Cases with age <50 y: $68.15 \%$. Regarding tumor stages, only $2.39 \%$ were presented in pT0 \& pT1 categories, and only $2.92 \%$ of 206 mastectomy cases were presented in stage 0 \& stage I, 12.7\% of cases were of grade I. Regarding the types: invasive ductal carcinoma, not otherwise specified type: 88\%, medullary type: $6.8 \%$, mucinous type: $2.1 \%$ \& invasive lobular type: $3.1 \%$. Left side $(179) /$ Right side $(113)=1.58$, and the bilaterality was $\mathbf{2 . 7 \%}$. Conclusion: Breast cancer rate among females in Western Iraq is low, but it is relatively higher in younger age group in comparison to other studies and mostly presented beyond early stage with a higher grade.
\end{abstract}

\section{Keywords}

Breast Cancer, Western Iraq, Anbar

\section{Introduction}

Breast cancer is the most frequently diagnosed cancer and cause of cancer death among women [1]-[3], ac- 
counting for $23 \%$ of the total cancer cases and $14 \%$ of the cancer deaths [4], and is the leading cause of death from cancer in low- and middle-income countries [1], where survival tends to be poorer, most likely because of a combination of a late stage at diagnosis and limited access to timely and standard treatment [4]. The incidence of breast cancer in Arab nations is significantly lower than that in Western nations, but the impression among Arab physicians dealing with breast cancer is that it presents at an earlier age and at a more advanced stage [5].

In Iraq, breast cancer is the most frequent cancer among women and accounts for approximately one-third of the registered female cancers [6]-[9].

The increased incidence in Western countries is well documented and is paralleled by stable or declining breast cancer mortality [1] [10], but in Eastern Mediterranean regions, they noticed obvious rise in the incidence rate, higher frequencies of younger ages and advanced stages at time of presentation, and the likely prevalence of more aggressive tumor that resulted in high mortality/incidence ratio [9]. The incidence rate of all female breast cancer in Iraq increased from 26.6 per 100,000 in 2000 to 31.5 per 100,000 in 2009, and is still affecting younger age group [7] [11].

In Iraqi hospital records, there is no proper documentation regarding critically important clinical factors such as tumor size, nodal status, stage distribution at the time of initial diagnosis, hormonal receptor status, proportion of women presenting with distant metastasis and proportion of patients treated with radical mastectomy versus breast conservation surgery [9], that is why we have to achieve academic articles dealing with such data to attain proper management standards in our region.

\section{Patients and Methods}

This is a descriptive study conducted between $1^{\text {st }}$ of February 2011 to $30^{\text {th }}$ of January 2015 and approved ethically by the scientific committee in Anbar medical college.

\subsection{Inclusion Criteria}

The included breast cancer cases (Number $=314$ cases) were collected from 4 public and 2 private hospitals in Anbar governorate (the largest governorate in Iraq that covers much of the country's west and inhabited by 1,598,822 people, Figure 1). Two histopathologists were approved these cases.

The following variables were included: age of patient, type, size, grade and side of tumor as well as the type of operation and lymph node status.

\subsection{Exclusion Criteria}

Male gender and cases that missed one or more of the following variables: Age of patient, size, grade, side \& type of the tumor were excluded (Number $=22$ ), the remaining 292 cases were enrolled in this study. Three cases of phyllodes tumor ( 2 benign and 1 borderline) had been already excluded.

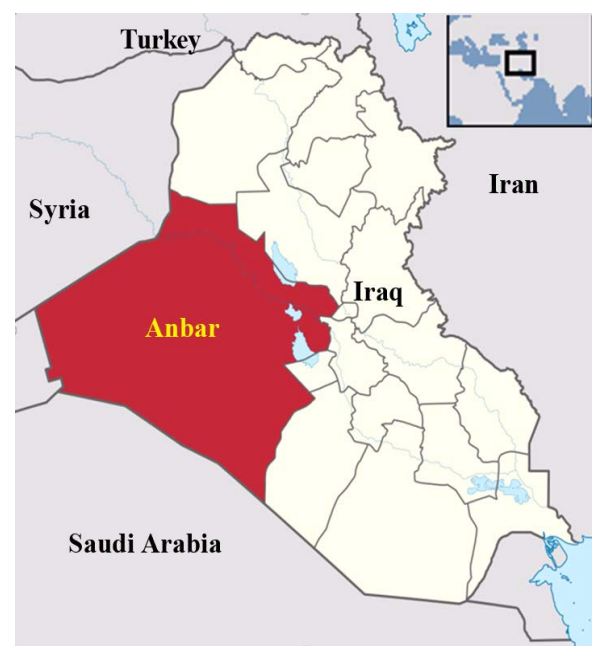

Figure 1. Anbar governorate in Western Iraq. 
Two hundred and six cases of the included 292, had mastectomy (including simple, modified and partial mastectomy) with axillary lymph nodes sampling, the remaining 86 cases were lumpectomies. American Joint Committee on Cancer $7^{\text {th }}$ edition was applied for staging [12], where we applied T category system for all (292) cases and TNM grouping system whenever the lymph node status was provided (206 cases).

Nottingham Histologic Score system (the Elston-Ellis modification of Scarff-Bloom-Richardson grading system) was applied [13].

\section{Results}

\subsection{Age of Presentation}

-Average age at diagnosis of breast cancer is 47.16 (SD: 12.15).

-Median age at diagnosis of breast cancer is 45, with mode of 40 (Table 1 \& Figure 2).

\subsection{Stage of Tumor at Presentation}

-T category for all cases $(n=292)$ :

$\mathrm{T} 0$ is $1 / 292=0.34 \%$.

$\mathrm{T} 1$ is $6 / 292=2.05 \%$.

$\mathrm{T} 2$ is $221 / 292=75.68 \%$.

$\mathrm{T} 3$ is $59 / 292=20.21 \%$.

$\mathrm{T} 4$ is $5 / 292=1.71 \%$.

-TNM staging system for provided lymph node status cases $(n=206)$ :

Table 1. Frequency distribution of age at presentation of breast cancer.

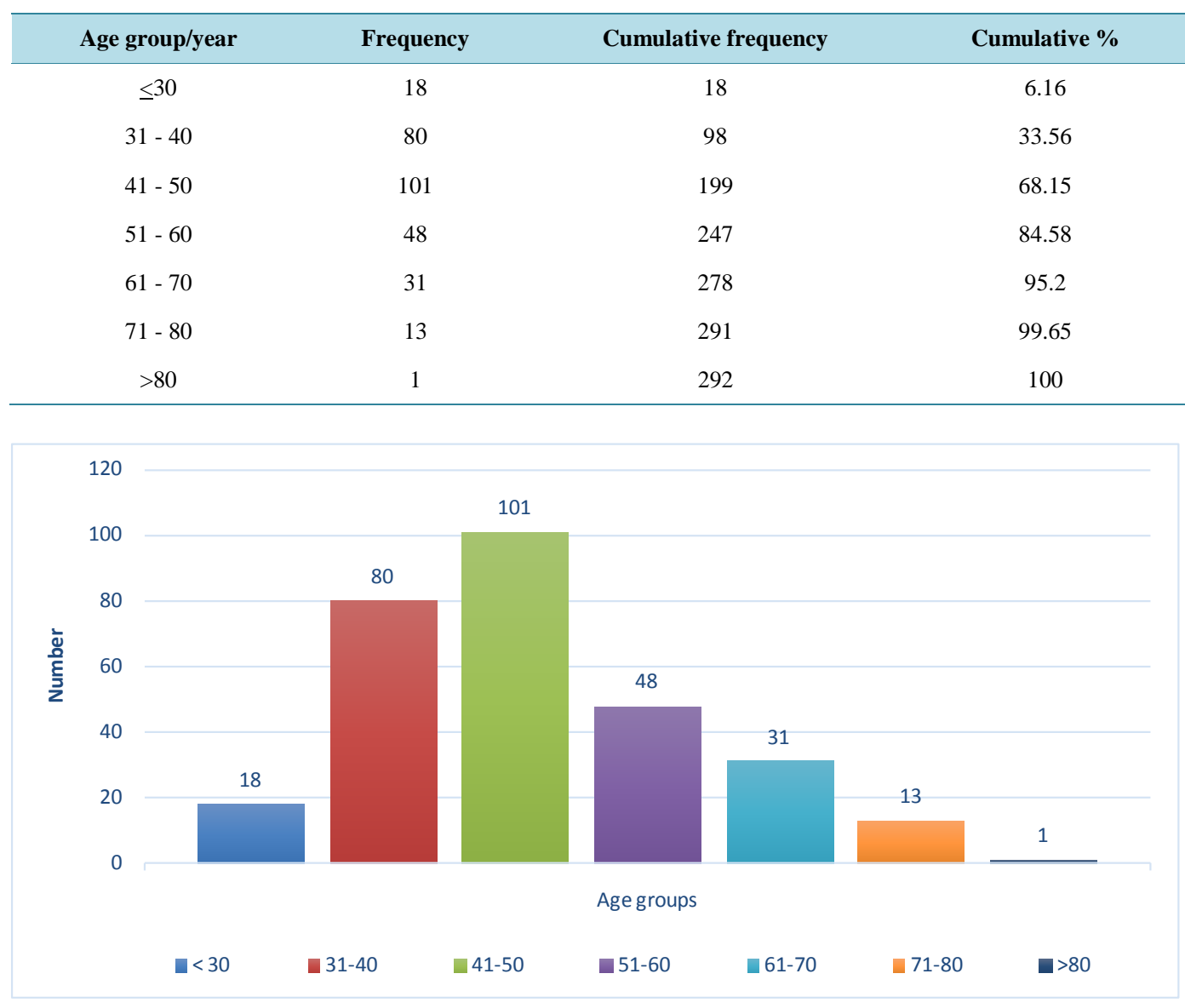

Figure 2. Age (year) distribution of breast cancer. 
Stage $0: 1 / 206=0.49 \%$.

Stage I: $5 / 206=2.43 \%$.

Stage II: $77 / 206=37.38 \%$.

Stage III: $119 / 206=57.77 \%$.

Stage IV: $4 / 206=1.94 \%$.

\subsection{Grades of Tumor}

$$
\begin{aligned}
& \text { I = 37/292 (12.7\%). } \\
& \text { II = 130/292 (44.5\%). } \\
& \text { III = 125/292 (42.8\%). }
\end{aligned}
$$

\subsection{Type of Tumor}

Invasive ductal carcinoma not otherwise specified, NOS: 257/292 = 88\%

Medullary: 20/292 $=6.8 \%$.

Mucinous: $6 / 292=2.1 \%$.

Invasive lobular: 9/292 = 3.1\% (Figure 3).

\subsection{Side of Tumor}

-Left side (179)/Right side (113) $=1.58$.

-Bilateral: $8 / 292=2.7 \%$.

\section{Discussion}

\subsection{Age of Presentation}

In this study, average age at diagnosis of breast cancer was 47.16 (SD: 12.15), which is similar to Runnak A Majid et al.'s study in Northern Iraq that was published in 2009 (47.4 + 11, p: 1.0001) [10], but it is significantly (p: 0.01) lower than that of the Molah Karim et al.'s study that was also performed in Northern Iraq in 2015 (49.4), [14] and also it is significantly (p: < 0.01) lower than that of the Divya A. Parikh et al.'s study in USA in 2015 with average of $59+13.07$ [15], and lower than that of Najjar and Easson's study that included 12 Arabic countries in 2010 [5] with average of $48+2.8$ as well as lower than that of Al-Hashimi and Wang's study that performed in Iraq in 2009 with average of 52 [7].

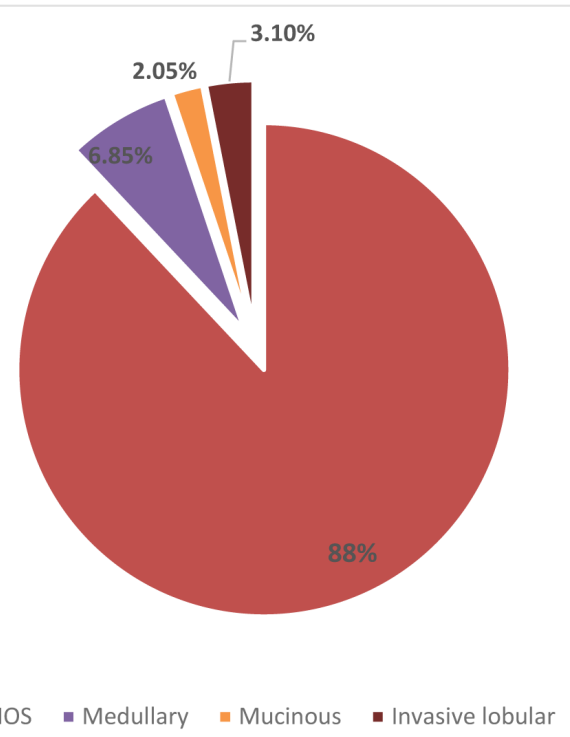

Figure 3. Types of breast carcinoma. 
World widely; around $6.6 \%$ of all breast cancer cases were diagnosed in women less than 40 of age [3] and in USA $6.7 \%$ of patients were $<40 \mathrm{y}$ and $29.8 \%$ were $<50$ y [15]. In this study, $66 \& 98$ patients out of 292 (22.6\% $\& 33.56 \%$ ) were $<40 \& \leq 40$ years old respectively, and 199 patients out of 292 (68.2\%) were $<50$ years old, where they are obviously higher than above stated word wide and USA indices, but they are compatible with Arabic study that included 8 Arabic countries $65.5 \%( \pm 11)[5]$.

As a conclusion regarding the age of presentation, this study revealed that among females in Western Iraq, breast cancer presentation is significantly earlier than the word wide age, including Arabic countries as well as other Iraqi regions.

The young average age of breast cancer patients in developing countries including the current study is probably not the result of an increase in breast cancer in young females but because of the relatively low incidence in older women [3] [8] and in such a conclusion, we have to answer the following question: why the incidence of breast cancer in older women in this region is relatively low but not so in young females?

The explanation could be at least partially related to the younger population in Iraq compared to western countries, as well as to the lower life expectancy of Iraqi females (73.8 year), compared to western countries that ranged from 81 to 87 years (WHO-2013), and this will be reflected in a low incidence rate in old age group, however, other genetic and environmental factors are to be considered including effects of consanguinity marriage that characterizes Iraqi community, role of hormonal replacement therapy, wars effect with use of unknown weapons, effects of parity, age of first pregnancy, length of reproductive life and prevalence of certain genes that are related to breast cancer in the Iraqi females, all these factors are to be investigated by a multifactorial study for more explanation.

\subsection{Stage of Tumor at Presentation}

In this study 7 cases out of 292 (2.4\%) were diagnosed in pT0 \& pT1 categories, and 6 cases out of 206 (2.92\%) of mastectomy cases with lymph nodes sampling were diagnosed in stage 0 \& stage I, this means that a minority of cases were diagnosed in early stage, while in USA, $61 \%$ of cases were diagnosed in stage I [10] and this is in agree with other studies which concluded that the majority of Ca-breast of young women in developing countries had been discovered in late stages [1] [5] [8] [10] and not only that, in the current study the early diagnosed cases were also lower than that of Northern Iraq where it was 4.1\% [10].

As a conclusion regarding breast cancer in Western Iraq, unfortunately only a minority of cases are diagnosed in early stage.

\subsection{Grades of Tumor}

Current study revealed that 37 out of 292 cases (12.7\%) are grade (I), 130 (44.5\%) cases are grade (II), and 125 (42.8) cases are grade (III), and it revealed that cases with grade III were corresponded to Nada Alwan-2014 study that performed in Iraq, where it represented about $40 \%$ of cases [9].

\subsection{Type of Carcinoma}

Regarding the rates of medullary and mucinous types, they were similar to other studies (Inhye Park et al. \& Kelli Y. et al.) [16] [17], but in comparison to other studies (Laure Dossus and Patrick R Benusiglio \& S Eva Singletary et al.), it shows lower rate of invasive lobular carcinoma and in turn higher rate of not otherwise specified type [18] [19]. To explain that, studies found that invasive lobular carcinoma is more likely associated with an advanced age and with the use of hormonal replacement therapy [18], so cases of lobular carcinoma seems to be decreased in this study due to younger age of presentation and lack of HRT. While most invasive breast cancers consist of carcinomas of the ductal type, about $10 \%$ are invasive lobular carcinomas. Invasive lobular and ductal carcinomas differ with respect to risk factors. Invasive lobular carcinoma is more strongly associated with exposure to female hormones, and therefore its incidence is more subject to variation. This is illustrated by US figures during the 1987 to 2004 period: after 12 years of increases, breast cancer incidence declined steadily from 1999 to 2004, reflecting among other causes the decreasing use of menopausal hormone therapy, and these variations were stronger for invasive lobular than for invasive ductal carcinoma. Similarly, invasive lobular carcinoma is more strongly associated with early menarche, late menopause and late age at first birth. As for genetic risk factors, four high-penetrance genes are tested in clinical practice when genetic suscep- 
tibility to breast cancer is suspected, BRCA1, BRCA2, TP53 and CDH1. Germline mutations in BRCA1 and TP53 are predominantly associated with invasive ductal carcinoma, while BRCA2 mutations are associated with both ductal and lobular cancers. CDH1, the gene coding for the E-cadherin adhesion protein, is of special interest as mutations are associated with invasive lobular carcinoma, but never with ductal carcinoma. It was initially known as the main susceptibility gene for gastric cancer of the diffuse type, but the excess of breast cancers of the lobular type in CDH1families led researchers to identify it also as a susceptibility gene for invasive lobular carcinoma. The risk of invasive lobular carcinoma is high in female mutation carriers, as about $50 \%$ are expected to develop the disease. Carriers must therefore undergo intensive breast cancer screening, with, for example, yearly magnetic resonance imaging and mammogram starting at age 30 years

\subsection{Side of Tumor}

The bi-laterality rate and left side predominance of tumor in this study were in agreement with all revised studies (studies of Khairy et al., Gong et al., Alan et al., Ahmed et al. \& Dane et al.) [20]-[24].

\section{Conclusion}

Breast cancer in Western Iraq is relatively low but it affects younger age group and is presented beyond early stage and with higher pathological grade.

\section{Recommendations}

-Establishment of screening test for breast cancer in earlier age and proper documentation system in Iraqi hospitals are important to attained proper management standards in our region.

-Multifactorial studies for factors that affect breast cancer in this region are to be considered, including hormonal replacement therapy, parity, age of first pregnancy, length of reproductive life and prevalence of certain genes that associated with breast cancer.

\section{References}

[1] Lauby-Secretan, B., Scoccianti, C., Loomis, D., Benbrahim-Tallaa, L., Bouvard, V., Bianchini, F., Straif, K., and International Agency for Research on Cancer Handbook Working Group (2015) Breast-Cancer Screening-Viewpoint of the IARC Working Group. The New England Journal of Medicine, 372, 2353-2358. http://dx.doi.org/10.1056/NEJMsr1504363

[2] Simmons, P.S., Jayasinghe, Y.L., Wold, L.E. and Melton III, L.P. (2011) Breast Carcinoma in Young Women. Obstetrics \& Gynecology, 118, 529-536. http://dx.doi.org/10.1097/AOG.0b013e31822a69db

[3] Assi, H.A., Khoury, K.E., Dbouk, H., Khalil, L.E., Mouhieddine, T.H. and El Saghir, N.S. (2013) Epidemiology and Prognosis of Breast Cancer in Young Women. Journal of Thoracic Disease, 5, S2-S8.

[4] Jemal, A., Bray, F., Center, M.M., Ferlay, J., Ward, E. and Forman, D. (2011) Global Cancer Statistics. CA: A Cancer Journal for Clinicians, 61, 69-90. Erratum in: CA: A Cancer Journal for Clinicians, 61, 134. http://dx.doi.org/10.3322/caac.20107

[5] Najjar, H. and Easson, A. (2010) Age at Diagnosis of Breast Cancer in Arab Nations. International Journal of Surgery, 8, 448-452.

[6] Tiwari, V., Pande, S.C., Verma, K. and Goel, S. (2015) Is Multiparity a Protective Mechanism in Iraqi Females with Breast Cancer? Need for Detailed Analysis. Clinical Cancer Investigation Journal, 4, 292-293. http://www.ccij-online.org/text.asp?2015/4/2/292/148933

[7] Al-Hashimi, M.M. and Wang, X.J. (2014) Breast Cancer in Iraq, Incidence Trends from 2000-2009. Asian Pacific Journal of Cancer Prevention, 15, 281-286. http://dx.doi.org/10.7314/APJCP.2014.15.1.281

[8] Majid, R.A., Mohammed, H.A., Hassan, H.A., Abdulmahdi, W.A., Rashid, R.W. and Hughson, M.D. (2012) A Population-Based Study of Kurdish Breast Cancer in Northern Iraq: Hormone Receptor and HER2 Status. A Comparison with ARABIC Women and United States SEER Data. BMC Women's Health, 12, 16. http://dx.doi.org/10.1186/1472-6874-12-16

[9] Alwan, N. (2014) Iraqi Initiative of a Regional Comparative Breast Cancer Research Project in the Middle East. Journal of Cancer Biology \& Research, 2, 1016.

[10] Majid, R.A., Mohammed, H.A., Saeed, H.M., Safar, B.M., Rashid, R.M. and Hughson, M.D. (2009) Breast Cancer in 
Kurdish Women of Northern Iraq: Incidence, Clinical Stage, and Case Control Analysis of Parity and Family Risk. BMC Women's Health, 9, 33. http://dx.doi.org/10.1186/1472-6874-9-33

[11] WHO (2012) GLOBOCAN 2012: Global Cancer Facts \& Figures. 3rd Edition, WHO, Geneva, 41.

[12] American Joint Committee on Cancer (AJCC) (2010) Breast Cancer Staging, New 7th Edition.

[13] Mazreku, J., Ziegler, K.L., Scocozza, M. and Brant, M.K. (2014) California Cancer Reporting System Standards, Volume I: Thirteenth Edition 2013, Version 2.3.

[14] Molah Karim, S.A., Ali Ghalib, H.H., Mohammed, S.A. and Fattah, F.H. (2015) The Incidence, Age at Diagnosis of Breast Cancer in the Iraqi Kurdish Population and Comparison to Some Other Countries of Middle-East and West. International Journal of Surgery, 13, 71-75. http://dx.doi.org/10.1016/j.ijsu.2014.11.029

[15] Parikh, D.A., Chudasama, R., Agarwal, A., Rand, A., Qureshi, M.M., Ngo, T. and Hirsch, A.E. (2015) Race/Ethnicity, Primary Language, and Income Are Not Demographic Drivers of Mortality in Breast Cancer Patients at a Diverse Safety Net Academic Medical Center. International Journal of Breast Cancer, 2015, Article ID: 835074.

[16] Park, I., Kim, J., Kim, M., Bae, S.Y., Lee, S.K., Kil, W.H., Lee, J.E. and Nam, S.J. (2013) Comparison of the Characteristics of Medullary Breast Carcinoma and Invasive Ductal Carcinoma. Journal of Breast Cancer, 16, 417-425. http://dx.doi.org/10.4048/jbc.2013.16.4.417

[17] Ha, K.Y., DeLeon, P. and DeLeon, W. (2013) Invasive Mucinous Carcinoma of the Breast. Proceedings (Baylor University. Medical Center), 26, 295-297.

[18] Dossus, L. and Benusiglio, P.R. (2015) Lobular breast Cancer: Incidence and Genetic and Non-Genetic Risk Factors. Breast Cancer Research, 17, 37. http://dx.doi.org/10.1186/s13058-015-0546-7

[19] Singletary, S.E., Patel-Parekh, L. and Bland, K.I. (2005) Treatment Trends in Early-Stage Invasive Lobular Carcinoma. Ann Surg, 242, 281-289.

[20] Khairy, G.A., Guraya, S.Y., Ahmed, M.E. and Ahmed, M.A. (2005) Bilateral Breast Cancer. Incidence, Diagnosis and Histological Patterns. Saudi Medical Journal, 26, 612-615.

[21] Gong, S.J., Rha, S.Y., Jeung, H.C., Roh, J.K., Yang, W.I. and Chung, H.C. (2007) Bilateral Breast Cancer: Differential Diagnosis Using Histological and Biological Parameters. Japanese Journal of Clinical Oncology, 37, 487-492. http://dx.doi.org/10.1093/jico/hym056

[22] Nicho, A.M., Yerushalmi, R., Tyldesley, S., Lesperance, M., Bajdik, C.D., Speers, C., Gelmon, K.A. and Olivotto, I.A. (2011) A Case-Match Study Comparing Unilateral With Synchronous Bilateral Breast Cancer Outcomes. Journal of Clinical Oncology (JCO), 29,4763-4768. http://dx.doi.org/10.1200/JCO.2011.35.0165

[23] Zeeneldina, A.A., Ramadanb, M., Elmashadc, N., Fakhrd, I., Diaaa, A. and Mosaada, E. (2013) Breast Cancer Laterality among Egyptian Patients and Its Association with Treatments and Survival. Journal of the Egyptian National Cancer Institute, 25, 199-207.

[24] Dane, S., Yildirim, S., Koc, M., Aktan, M. and Gundogdu, C. (2008) Asymmetries in Breast Cancer Lateralization and Both Axillary Lymph Node Number and Metastatic Involvement. Lymphology, 41, 75-79. 